\title{
The Percentage of Deaths Under One Year of Age of All Deaths in Finland in 1749-1865
}

\author{
OIVA TURPEINEN
}

\author{
Assistant \\ Department of History \\ University of Helsinki
}

\section{Introduction}

In research on population history, in general, and especially in research on mortality the development of infant mortality is a very important factor. The causes of infant mortality are connected in many ways to society, such as to economic factors, medical conditions, child care, etc. In preindustrial times, infant mortality was also a central part of mortality; also, when studying fertility, changes and regional differences in infant mortality must be taken into account. Infant mortality is usually measured by comparing the number of deaths under the age of one to the number of live births in the corresponding period. In the following, however, the approach is slightly different. The purpose here is to examine the proportion of deaths under one year of age of all deaths occurring in the period 1749-1865. The main emphasis is thus especially on regional comparison and on changes in different regions in the period under examination.

\section{Annual development}

Figure 1 shows the annual development of infant mortality and the percentage of all deaths formed by deaths under the age of one. At the end of the $1700 \mathrm{~s}$ this percentage was $31.9 \%$, but in the beginning of the $1800 \mathrm{~s}$ it was down to $26.9 \%$. At the same time infant mortality dropped from 217.6 per thousand to 197.5 per thousand. It should be noted that, in periods of crisis, infant mortality rose dramatically, but the proportion of deaths under one year of age of all deaths declined. This occurred, for example, in 1788-91, 1808-09, 1832-33 and 1857. This can be explained partly by increased mortality in age groups other than that under one year of age and because the number of births dropped in these periods of crisis. 
F i g u r e 1. Infant mortality in Finland 1749-1865.

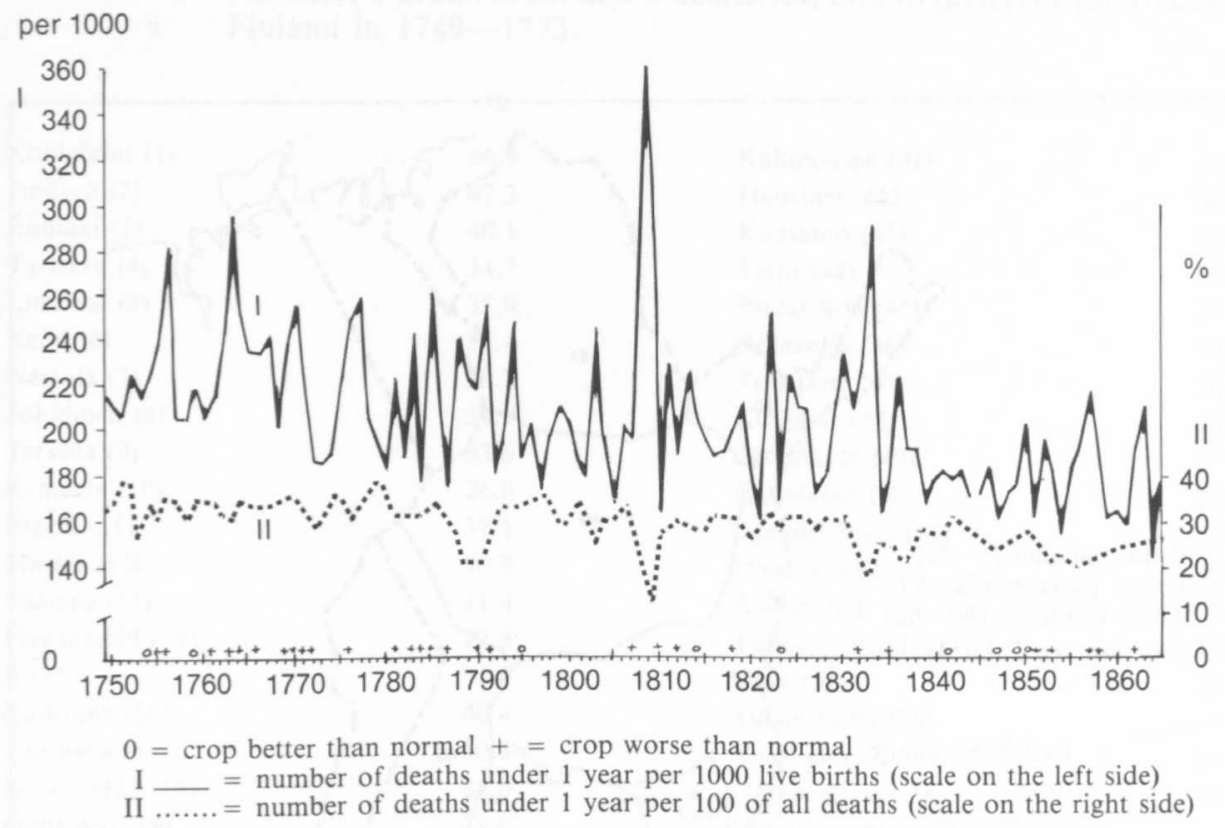

\section{Regional differences in 1749-73}

In order to analyze regional differences, a sample was selected from the period 1749-73 including 51 rural parishes, 8 urban parishes and 3 deaneries. Thus we can form a markedly more exact picture of what happened than would be provided by a mere examination of the different provinces (Figures 2, 3, and Table 1).

On the province level the province of Pohjanmaa forms an entity of its own which clearly differs from the other provinces: here the proportion of deaths under one year of age of all deaths was about one-half. Inside the province, however, there were vast differences. Thus the proportion in the deanery of Pietarsaari was about $59 \%$ and in Koivulahti an entire $67 \%$. Correspondingly, in sparsely settled areas the percentage remained under 20 , which at least partly was caused by the fact that some of those who died at a very young age were never registered.

All the other areas come between these two extremes with a percentage of around 30 or a little less, thus close to the average of the three other provinces.

\section{The situation in $1792-1805$}

In 1792-1805 deaths under one year of age formed $31.6 \%$ of all deaths, thus meaning a decline of 2.1 percentage points compared to $1749-73$. The highest 
F i g u r e 2. Sample districts.

Rural parishes (1-51)

Urban parishes $(52-59)$

Three deaneries $(60-62)$

(For key see Table 1)

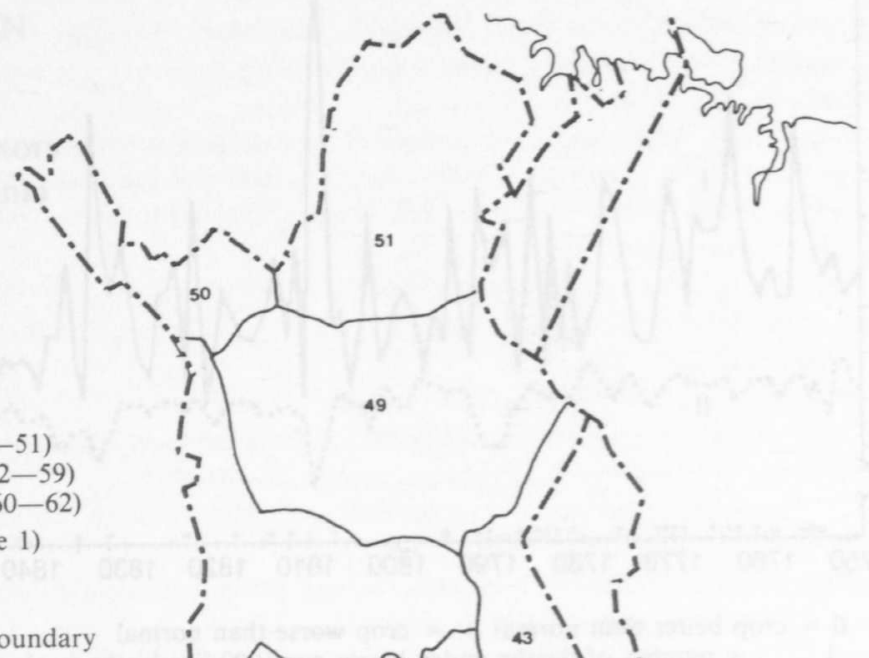

arish boundary

- $=$ town

deanery of

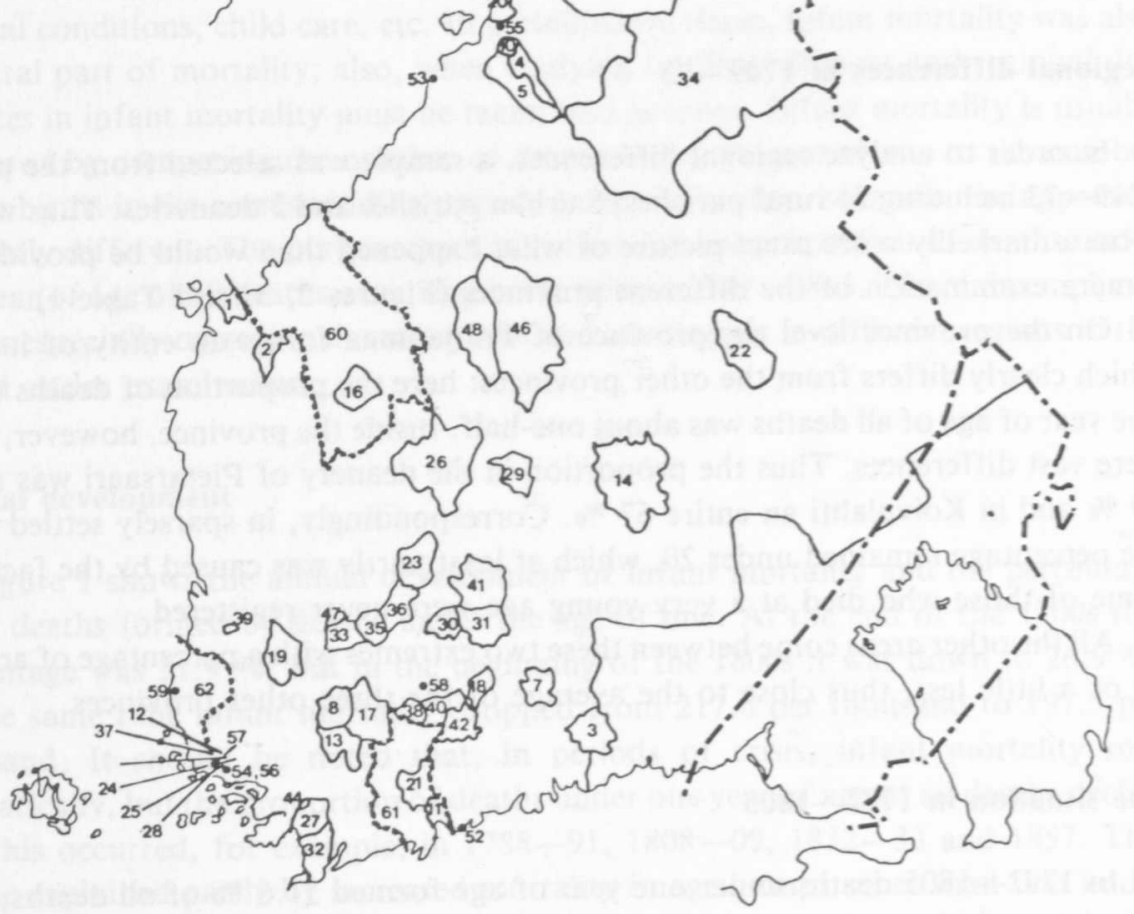


$\mathrm{T}$ a b l e 1. Deaths under one year of age as a percentage of all deaths in 51 rural parishes, 8 urban areas and 3 deaneries, and in different provinces in Finland in 1749-1773.

\begin{tabular}{|c|c|c|c|}
\hline Koivulahti (1) & 66.9 & Kuhmoinen (41) & 25.2 \\
\hline Isokyrö (2) & 47.3 & Hausjärvi (42) & 30.6 \\
\hline Elimäki (3) & 40.1 & Kuusamo (43) & 30.9 \\
\hline Tyrnävä (4) & 34.7 & Teijo (44) & 22.5 \\
\hline Liminka (5) & 35.9 & Pudasjärvi (45) & 21.8 \\
\hline Kemi (6) & 36.4 & Viitasaari (46) & 15.9 \\
\hline Nastola (7) & 30.7 & Tottijärvi (47) & 26.0 \\
\hline Jokioinen (8) & 34.9 & Kivijärvi (48) & 20.8 \\
\hline Tervola (9) & 35.6 & Sodankylä (49) & 27.2 \\
\hline Kempele (10) & 26.0 & Enontekiö (50) & 26.0 \\
\hline Espoo (11) & 32.1 & Utsjoki/Inari (51) & 14.9 \\
\hline Masku (12) & 30.9 & Helsinki (52) & 30.6 \\
\hline Somero (13) & 31.4 & Raahe (53) & 35.7 \\
\hline Pieksämäki (14) & 22.4 & Turku, Finnish (54) & 29.9 \\
\hline Ii (15) & 31.0 & Oulu $(55)$ & 35.9 \\
\hline Kuortane (16) & 40.4 & Turun linna (56) & 27.2 \\
\hline Tammela (17) & 30.3 & Naantali (57) & 26.0 \\
\hline Koski (HL) (18) & 25.6 & Hämeenlinna (58) & 32.9 \\
\hline Huittinen (19) & 29.9 & Uusikaupunki (59) & 28.3 \\
\hline Haukipudas (20) & 27.9 & Pietarsaari (60) & 59.3 \\
\hline Vihti (21) & 29.7 & Lohja (61) & 30.2 \\
\hline Kaavi (22) & 19.8 & Vehmaa (62) & 28.6 \\
\hline Orivesi (23) & 32.0 & & \\
\hline Maaria (24) & 29.2 & 51 rural parishes & 30.9 \\
\hline Rusko (25) & 31.9 & Urban areas & 31.2 \\
\hline Keuruu (26) & 28.5 & Rural and urban areas & 31.0 \\
\hline Perniö (27) & 27.5 & 3 deaneries & 44.1 \\
\hline Raisio (28) & 26.1 & & \\
\hline Jyväskylä (29) & 33.3 & ENTIRE SAMPLE & 35.8 \\
\hline Luopioinen (30) & 34.6 & Turku and Pori (I) & 30.8 \\
\hline Padasjoki (31) & 29.5 & Häme and Uusimaa (II) & 29.6 \\
\hline Tenhola (32) & 31.9 & Savo and Karjala III) & 25.1 \\
\hline Vesilahti (33) & 33.3 & Pohjanmaa (IV) & 49.1 \\
\hline Paltamo (34) & 29.4 & & \\
\hline Lempäälä (35) & 20.8 & All of Finland & 33.7 \\
\hline Kangasala (36) & 28.3 & $1-51=$ Rural parishes & \\
\hline Lemu (37) & 27.8 & $\begin{aligned} 1-51 & =\text { Rural parishes } \\
52-59 & =\text { Urban parishes }\end{aligned}$ & \\
\hline Renko (38) & 28.5 & & \\
\hline Harjavalta (39) & 24.4 & $60-62=$ Deaneries & \\
\hline Janakkala (40) & 23.5 & $\mathrm{I}-\mathrm{IV}=$ Provinces & \\
\hline
\end{tabular}

percentages continued to concentrate in Western Finland, especially in Southern and Central Pohjanmaa and the Åland Islands. In the deanery of Pietarsaari, an average of every other person buried was less than one year old and in the Aland Islands four out of ten deaths were those of children under one year of age (Figure 4 and Table 2). 
$\mathrm{F}$ i g u r e 3. Deaths under one year of age as a percentafe of all deaths in Finland by province in $1749-1773$.

All of Finland $=33.7 \%$.

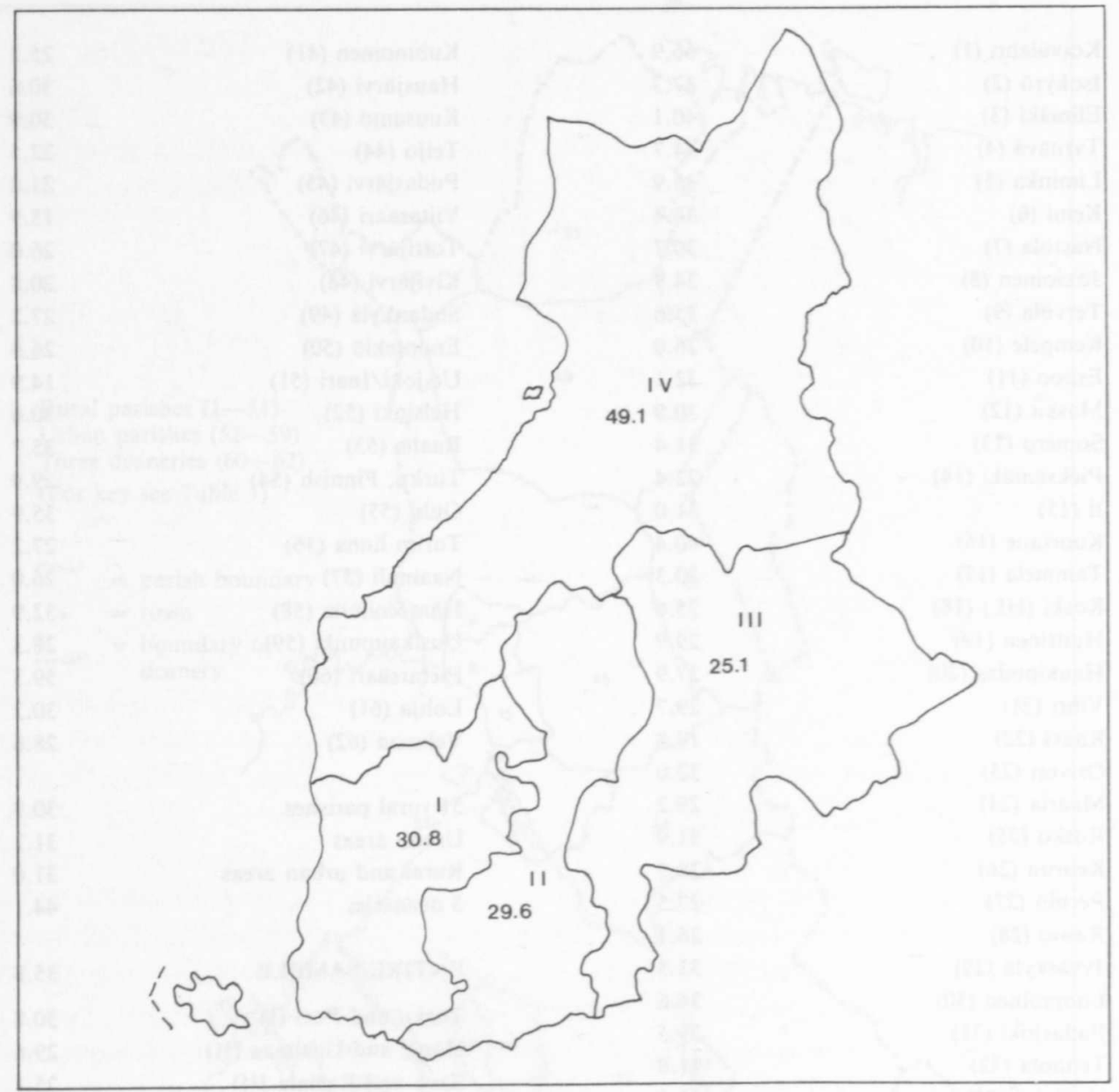

About one-third of all deaths were under one year of age in the Northern Pohjanmaa deaneries of Raahe and Kemi and in Eastern Finland in the deaneries of Porvoo, Kymi and Eastern Häme. In the other regions the percentage fluctuated between 20 and 30 .

\section{The years $1841-65$}

In the $1800 \mathrm{~s}$, before industrialization, the declining tendency continued, even accelerating somewhat. In 1841-65 the proportion deaths under one year of age made up of all deaths had dropped to slightly less than one-fourth. The most rapid decline was expressly in Southern and Central Pohjanmaa and in the Alland Islands. Thus, the percentage in the deanery of Pietarsaari, which in 1749-73 had been 59.3, 
$\mathrm{Fi} \mathrm{g} \mathrm{u} \mathrm{r} \mathrm{e} \mathrm{4.} \mathrm{Deaths} \mathrm{under} \mathrm{one} \mathrm{year} \mathrm{of} \mathrm{age} \mathrm{as} \mathrm{a} \mathrm{percentage} \mathrm{of} \mathrm{all} \mathrm{deaths} \mathrm{in} \mathrm{Finland}$ by deanery in $1792-1805$.

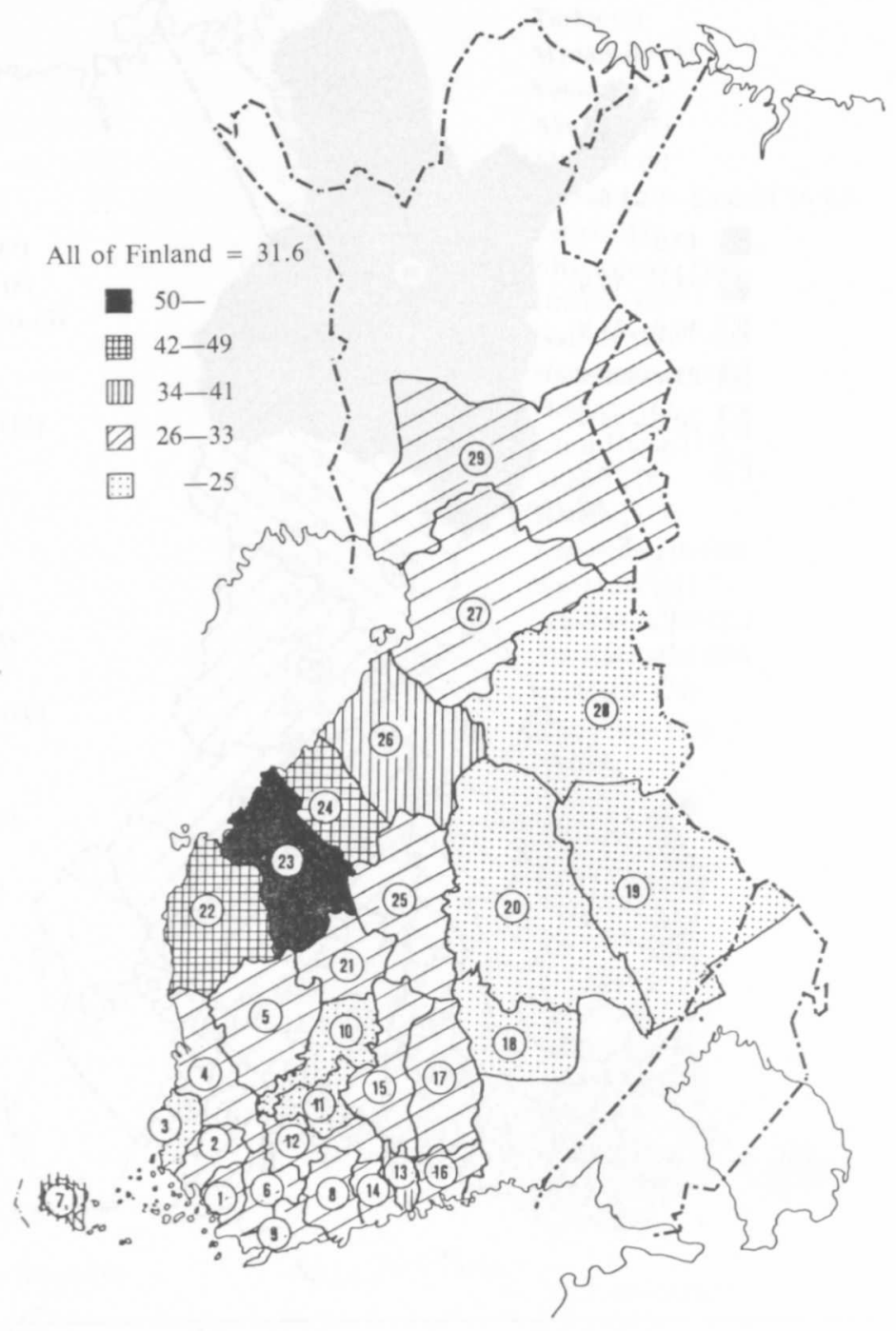

dropped already to $52.3 \%$ in $1792-1805$ and all the way to 36.3 in $1841-65$. In the deanery of Kokkola the corresponding figures in 1792-1805 and 1841-65 were $48.8 \%$ and $30.3 \%$ and in the Åland Islands $41.2 \%$ and $26.0 \%$. The percentage dropped clearly in many other districts also, but not nearly as steeply (Figure 5 and Table 2). 
$\mathrm{Fig} \mathrm{u} \mathrm{re} \mathrm{5.} \mathrm{Deaths} \mathrm{under} \mathrm{one} \mathrm{year} \mathrm{of} \mathrm{age} \mathrm{as} \mathrm{a} \mathrm{percentage} \mathrm{of} \mathrm{all} \mathrm{deaths} \mathrm{in} \mathrm{rural}$ Finland by deanery $1841-65$.

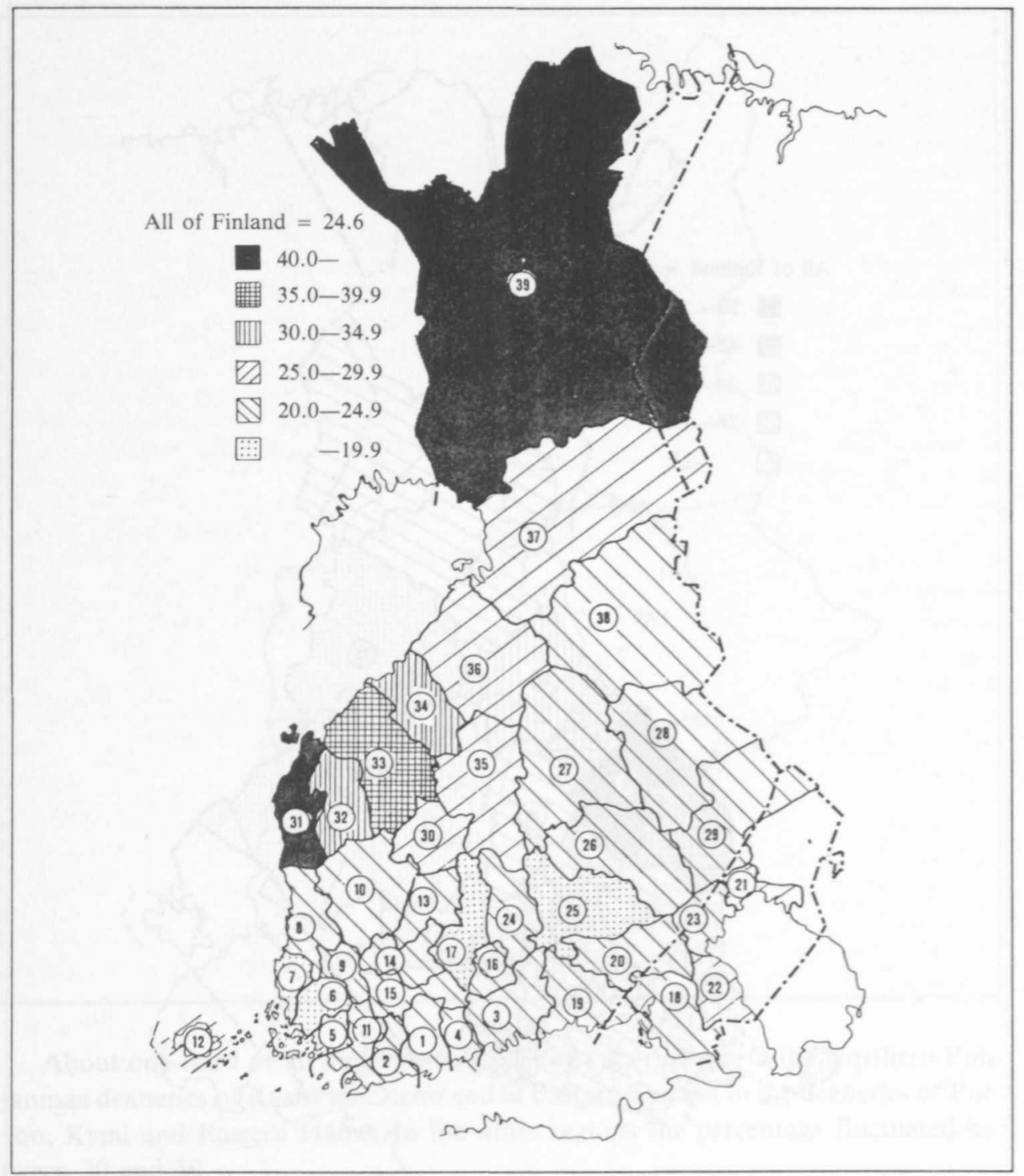

\section{Final conclusions}

The proportion of all deaths occurring under one year of age and the decline in this figure in Finland as a whole and especially in various regions in Western Finland was, of course, connected to the decline in infant mortality. Indirectly, the percentage was also affected by the development of mortality in the over-one-year-old 
T a b l e 2. Number of deaths under 1-year per 100 of all deaths in Finland $1792-1805$ and $1841-65$.

$1792-1805$

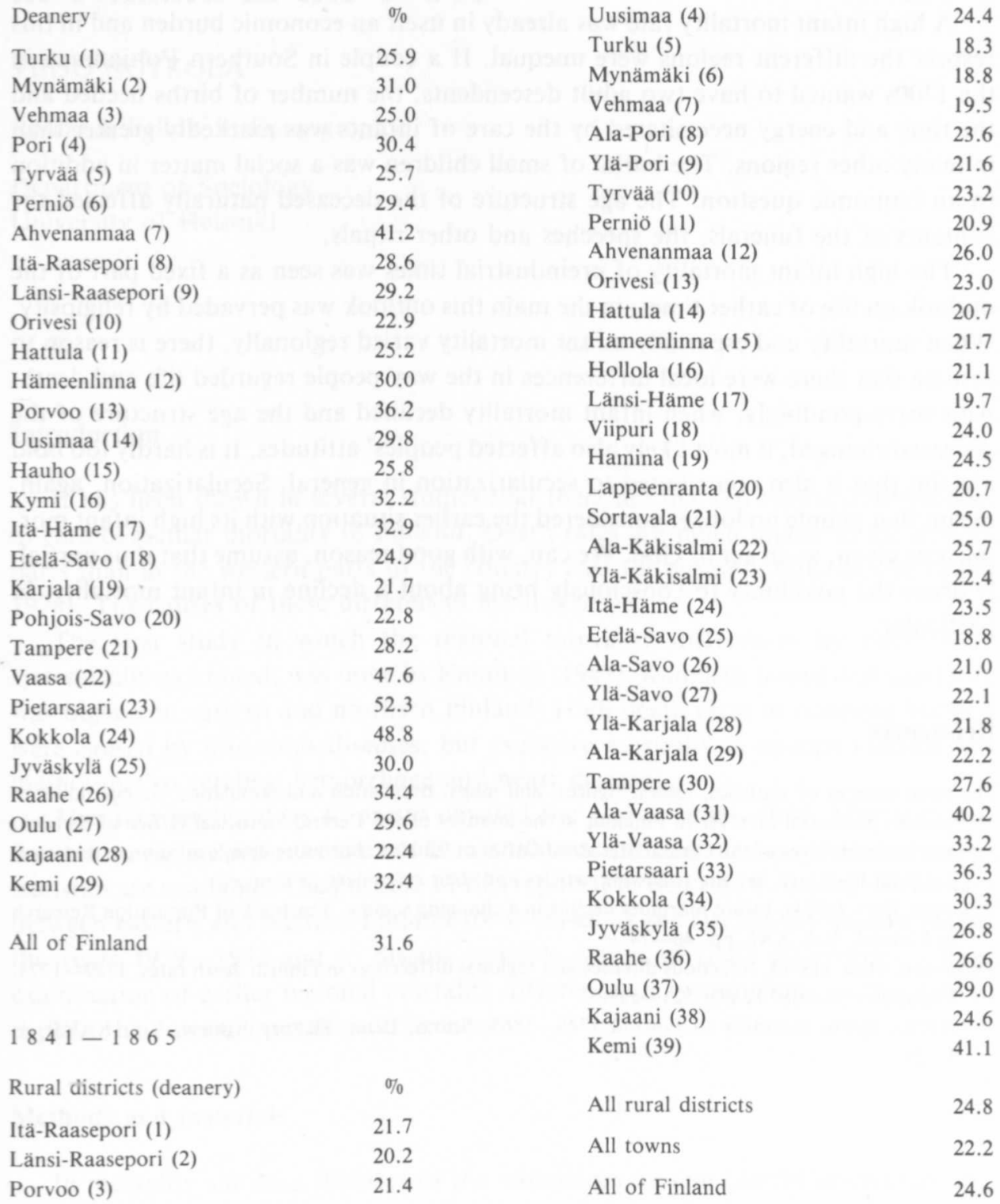

group. When, for example, tuberculosis became more common, it especially took its toll on the middle-aged population, which was at least partly visible as a decline in the percentage of deaths under one year of age.

In this context there is no cause for a more detailed examination of the reasons 
for the decline in infant mortality in the $1700 \mathrm{~s}$ and the $1800 \mathrm{~s}$, not of causes of death in general. On the other hand, there is reason to emphasize the social, economic and ideological significance of the exceptionally high number of deaths occurring at an early age and of the decline in these deaths already before industrialization.

A high infant mortality rate was already in itself an economic burden and in this respect the different regions were unequal. If a couple in Southern Pohjanmaa in the 1700 s wanted to have two adult descendents, the number of births needed and the time and energy necessitated by the care of infants was markedly greater than in many other regions. The burial of small children was a social matter in addition to an economic question. The age structure of the deceased naturally affected the contents of the funerals, the speeches and other rituals.

The high infant mortality of preindustrial times was seen as a fixed part of the outlook on life of earlier times; in the main this outlook was pervaded by religiosity. When mortality and especially infant mortality varied regionally, there is reason to assume that there were local differences in the way people regarded life and death. And correspondingly, when infant mortality declined and the age structure of the deceased changed, it most likely also affected peoples' attitudes. It is hardly too bold a claim that it also contributed to secularization in general. Secularization, again, meant that people no longer considered the earlier situation with its high infant mortality as given, as an act of God. We can, with good reason, assume that thus partially arose the possibility to consciously bring about a decline in infant mortality, in particular.

\section{References}

The main sources of statistics, tables, figures, and maps: population and population change tables in various provincial archives in Finland, in the archives of the Central Statistical Office of Sweden, and in the archives of the Central Statistical Office of Finland. For more details on sources and especially on literature, see the following articles and their references to sources.

Pitkänen, Kari. (1983). Infant mortality decline in a changing society. Yearbook of Population Research in Finland, Vol. XXI, pp. 46-74.

Turpeinen, Oiva. (1978). Infectious diseases and regional differences in Finnish death rates, 1749-1773. Population Studies 32 (3): 523-533.

-. (1979). Infant mortality in Finland 1749-1865. Scand. Econ. History Review, Vol. XXVII, 1: $1-21$. 